\title{
Uma análise da metodologia Just-In- Time e do sistema Kanban de produção sob o enfoque da ciência da informação
}

\section{Lúcia Filomena de Almeida Guimarães}

\author{
Professora do Curso de Engenharia \\ da Computação Puc-Campinas e \\ Coordenadora do Curso de \\ Matemática, UNIP- Campinas
}

\section{Orandi Mina Falsarella}

\section{Professor do Mestrado em Ciência da Informação, Puc-Campinas}

A Ciência da Informação estuda os diversos aspectos da informação, envolvendo produção, organização, recuperação e distribuição. Dentro de uma empresa, a metodologia Just In Time (JIT) busca o atendimento das necessidades dos clientes, garantindo qualidade $e$ trabalhando com o mínimo possível de estoque. Assim, uma análise da importância da informação neste ambiente é apresentada, mostrando que o foco e a base de todos os conceitos e ferramentas do JIT é a informação como pilar para o conhecimento estratégico efetivo.

Palavras-chave: Informação; Conhecimento; Metodologia Just-in-Time; Sistema Kanban de Produção.

\section{An Analisys of Just-in-Time Methodology and Kanban Production System under the Information Science point of view}

Information Science studies the different aspects of information such as production, organization, retrieving and distribution. The Just-in-Time Methodology, in a business, attempts to fulfill the client's needs, maintaining the quality and working with the minimum inventory possible. Then, an analysis of the importance of the 
information in this environment is presented showing that the focus and basis of all Just-in-Time concepts and tools are information as the pillars of the effective strategic knowledge.

Keywords: Information; Knowledge; Just-in-Time Methodology; Kanban Production System.

Recebido em 31.12.2007Aceito em 18.06.2008

\section{Introdução}

A Ciência da Informação tem como objetivo o estudo da produção, organização, distribuição e fluxo da informação (BARRETO, 2001). Este estudo visa criar mecanismos que reduzam as incertezas criando um processo de comunicação efetiva, em que todo o conteúdo transmitido do emissor ao receptor seja assimilado corretamente, trazendo benefícios e desenvolvimento. É uma ciência complexa, constituída de várias vertentes, que procura avaliar e adequar os diversos conceitos existentes para as diferentes realidades.

Le Coadic (1996) afirma que "informação é um conhecimento. Conhecer é ser capaz de formar a idéia de alguma coisa". Gerar, obter e aplicar conhecimento, de acordo com Valentim (2002), é o item básico para enfrentar uma sociedade em constante movimento e conseqüente mudança. A sociedade da informação, alicerçada na informação, na comunicação, na telecomunicação e nas tecnologias de informação, procura criar novos caminhos de desenvolvimento que atendam a estas mudanças sociais.

O ambiente criado por esta nova sociedade é mais competitivo e exigente, fazendo com que as organizações desenvolvam ferramentas para acompanhar essas alterações com rapidez e sem grandes perdas. Huotari e Wilson (2001) definem o comportamento organizacional da informação como sendo os sistemas e serviços básicos da organização, designados para adquirir, compartilhar e disseminar todos os tipos de informação, dos dados de produção das fábricas aos eventos do mercado.

Seguindo estas necessidades, de constante mudança, no início da década de 70 foi criado o Sistema de Produção Toyota na Toyota Motor Company. Este sistema foi elaborado sob dois pilares básicos (ROSES, 2001): o Just-in-Time (JIT) e a automação. Entende-se por automação ("jidoka" em japonês) o controle autônomo de defeitos. Ela apóia o JIT por nunca permitir que unidades defeituosas de um processo precedente continuem no fluxo de produção, atrapalhando o processo subseqüente (MONDEN, 1986)

O JIT é a metodologia que busca o atendimento das necessidades dos clientes no menor prazo possível, garantido qualidade e trabalhando com o mínimo de estoque. Pode ser descrito como sendo uma metodologia que está constantemente buscando a integração da 
organização, através do processo mais simples para permitir que o processo de mudança, direcionado pelas necessidades da sociedade, seja atendido com maior rapidez e sem desperdício.

Essa metodologia procura eliminar qualquer tipo de desperdício dentro de uma indústria, garantindo, assim, a competitividade. $O$ desperdício não é identificado prontamente no balaço da empresa. Ele se manifesta nos altos estoques, na baixa qualidade, no longo tempo de fabricação e na movimentação de material freqüente e em demasia (GUIMARÃES, 1998).

Um dos elementos desta metodologia é o Sistema Kanban de Produção, que é um sistema de chão de fábrica baseado no princípio de que o material de produção é "puxado" pelo sistema à medida que se torna necessário. Ou seja, dentro do sistema de produção, uma operação de um nível mais avançado engatilha o início do trabalho em uma operação predecessora (anterior).

O objetivo deste trabalho é avaliar a importância da informação dentro de uma organização que utiliza a metodologia JIT e o sistema Kanban de Produção, bem como a geração de conhecimento dentro das organizações e o modo como isto influencia suas relações internas e externas.

Como método de pesquisa foi utilizada a pesquisa bibliográfica, onde são apresentados os principais conceitos associados a dado, informação e conhecimento, dentro do contexto da Ciência da Informação, e a definição da metodologia JIT e do Sistema Kanban de Produção. Este estudo permitiu a análise do fluxo das principais informações na aplicação da metodologia JIT e do Sistema Kanban, e a produção de novos conhecimentos, nesta Área, dentro das organizações.

Vários autores têm discutido a definição dos conceitos associados à Ciência da Informação.

Barreto (2001) define informação como uma estrutura com intenção de gerar conhecimento no indivíduo e seu espaço.

Já Fernadez-Molina (1994) avalia a informação sob dois diferentes enfoques: objetivo (a informação como algo físico) e subjetivo (a informação como algo cognitivo).

Para Buckland (1991), existem três significados distintos para informação: a informação como processo (ação de contar sobre alguma coisa, 0 ato de informar); a informação como conhecimento (o conhecimento comunicado sobre um fato, ou seja, a informação intangível); e a informação como uma coisa (a informação obtida através de eventos e objetos, ou seja, a informação tangível).

De acordo com Setzer (2001), a informação seria uma abstração informal (não pode ser formalizada através de uma teoria lógica ou matemática), que está na mente de alguém, representando algo significativo para essa pessoa.

Os conceitos de diversos autores são discutidos por Valentim (2002), que opta pela definição de Davenport e Prusak (1999): a informação são dados dotados de relevância e propósito. O autor mostra 
também que o importante é optar pela definição que mais se adequa ao trabalho que está sendo desenvolvido.

Neste trabalho adotam-se os conceitos apresentados por Miranda (1999):

Dados: conjunto de registros, qualitativos ou quantitativos, conhecido, que, organizado, agrupado, caracterizado e padronizado adequadamente, transforma-se em informação; Informação: dados organizados de modo significativo, sendo subsídio útil à tomada de decisão; Estratégia: ação gerada a partir de informações que levam à criatividade, à originalidade e à inovação; Informação estratégica: informação obtida do monitoramento estratégico, que subsidia a formulação de estratégias pelos tomadores de decisão nos níveis gerenciais da organização; Informação não estratégica ou de acompanhamento: informação obtida do monitoramento interno, que, aliada à informação estratégica, constitui-se em conhecimento estratégico explícito; Conhecimento explícito: conjunto de informações já elicitadas em algum suporte (livros, documentos, etc.) que caracteriza o saber disponível sobre o tema específico; Conhecimento tácito: acúmulo do saber prático sobre determinado assunto; Conhecimento estratégico: combinação de conhecimento explícito e tácito; Monitoramento externo ou estratégico: observação sistemática e coleta de dados do ambiente externo à organização; Monitoramento interno ou acompanhamento: observação sistemática e coleta de dados do ambiente interno à organização.

Nonaka e Takeuchi (1997) defendem a idéia de que o conhecimento tácito e o conhecimento explícito não são entidades totalmente separadas, e sim mutuamente complementares, que interagem um com o outro e realizam trocas nas atividades criativas dos seres humanos. O modelo dinâmico da criação do conhecimento apresentado por eles está ancorado no pressuposto crítico de que o conhecimento humano é criado e expandido através da interação entre 0 conhecimento tácito $e \quad 0$ conhecimento explícito. Essa interação é denominada de "conversão do conhecimento" e é um processo "social" entre indivíduos, e não confinada dentro de um indivíduo.

Os autores, afirmam que a criação do conhecimento nas empresas japonesas resume-se à conversão do conhecimento tácito em conhecimento explícito, baseado em três características:

- Utilização de linguagem figurada e simbolismo para explicar o inexplicável. É uma forma de fazer com que indivíduos fundamentados em diferentes contextos e com diferentes experiências compreendam algo intuitivamente através do uso da imaginação e dos símbolos. Nenhuma análise é necessária;

- Transmissão do conhecimento: o conhecimento pessoal de um indivíduo deve ser compartilhado com outros. A organização 
não pode criar conhecimento por si mesma, sem a iniciativa do indivíduo e a interação que ocorre dentro do grupo. A interação dinâmica, através do trabalho em equipe, facilita a transformação do conhecimento pessoal em conhecimento organizacional. As equipes têm papel central na criação de conhecimento, pois permitem a interação entre os indivíduos através do diálogo e do debate. Os conflitos que surgem impulsionam os indivíduos a questionarem as premissas existentes e a compreenderem suas experiências de uma nova forma;

- Ambigüidade e redundância, através das quais surgem novos conhecimentos. A ambigüidade gera, dentro de uma equipe, confusão e questionamento, que podem vir a ser útil como fonte de um novo senso de direção, mas também como fonte de significados novos, de uma forma diferente de pensar. Nesse sentido, o conhecimento nasce do caos. Já a redundância é importante porque estimula o diálogo freqüente e a comunicação. Uma vez que as informações são compartilhadas, os membros de uma organização podem sentir o que os outros estão tentando articular. A redundância, que ocorre principalmente no compartilhamento das idéias, também difunde o conhecimento explícito pela organização, permitindo sua internalização pelos funcionários.

Miranda (1999) apresenta também os tipos de informação estratégica para uma empresa. Dentre as quais se ressalta o de Fornecedor, que são informações sobre o perfil, atitudes, localização, opções de fontes de fornecimento, condições de transporte, preços, prazos de pagamento, descontos, entrega, tendências quanto à formação de parcerias, etc.

As características da informação estratégica são:

- Qualitativa: refere-se a informações consolidadas a partir de dados que em sua maioria são não-numéricos;

- Quantitativa: refere-se a informações consolidadas a partir de dados que em sua maioria são numéricos.

- Mista: refere-se a informações consolidadas a partir de dados numéricos e não-numéricos, sendo que não se é possível estabelecer a predominância de um sobre o outro em sua formação.

\section{A metodologia JIT e o sistema Kanban de produção}

Segundo Buffa (1987), uma empresa pode ser vista como um sistema criado pelo homem, que mantém uma interação dinâmica com seu meio ambiente (influi e recebe influência dele). É um sistema integrado por diversas partes, que trabalham em harmonia, com a finalidade de alcançar uma série de objetivos. Ou seja, ela tem como objetivo receber uma série de insumos do meio ambiente e transformá-los 
ou converte-los em produtos e serviço que são exportados para o meio novamente.

A empresa tratada neste trabalho é aquela que tem suas atividades voltadas para a produção de bens (produtos). Basicamente, ela é dividida em três áreas que interagem entre si: Marketing (age com o meio externo, avaliando preferências, tendências, procurando estabelecer previsão de demanda e processo de distribuição); Finanças (concentra-se na obtenção e administração do capital no sentido de operacionalidade da empresa); e Produção (processo de transformação da matéria prima em produtos, provendo um conjunto específico de serviços).

A interdependência destas três áreas é grande. Ter recursos financeiros e habilidade de produzir é de pouca valia quando não existe mercado para vender os produtos. Ter recursos financeiros e mercado não adianta se não se pode produzir. A existência de um mercado e a habilidade de produção não são suficientes se não existe o capital necessário. Cada área tanto contribui para a empresa como um todo, como depende das outras áreas remanescentes.

Portanto, Marketing e Finanças ocupam-se das necessidades ou dos resultados da área de Produção e, consequentemente, requerem um bom gerenciamento. O Planejamento e Controle de Produção (PCP) trata deste gerenciamento, coordenando todas as atividades, desde a aquisição da matéria prima até a entrega do produto final. A estrutura organizacional do sistema PCP reúne três fases distintas de planejamento (Vollmann, 1997):

- Estratégico: tem como objetivo decidir as políticas adequadas na realização das metas de longo prazo da empresa, que são tomadas pelas três áreas básicas;

- Tático: está relacionado com a implementação das estratégias definidas no planejamento estratégico. Tem como objetivo o gerenciamento da demanda, o planejamento da produção e a utilização de recursos e decisões sobre níveis de estoque;

- Operacional: trata das decisões do dia a dia, tendo como função a programação detalhada da produção.

No contexto empresarial, JIT é uma metodologia de gerenciamento, um enfoque de sistema integrado para otimizar a utilização dos recursos da empresa. Sua idéia fundamental é a eliminação total de perdas no processo de produção. Entende-se por perdas tudo aquilo que excede a quantidade exata de material, mão-de-obra, máquinas e ferramentas necessárias para a produção.

Ela engloba um conjunto de técnicas e conceitos que tem como finalidade a melhoria contínua do sistema de produção. Essa melhoria pode ser interpretada como uma otimização dos processos e dos procedimentos de produção, com redução sistemática dos desperdícios. Entende-se por desperdício todas as atividades realizadas na fábrica que não agregam valor à produção, tais como desperdício de produzir itens defeituosos, desperdício de movimento e desperdício de estoque. 
Enfatiza, também, o fluxo contínuo de produção, ou seja, os produtos fluem de forma suave e contínua através das diversas fases do processo produtivo. Seus principais objetivos são:

- redução contínua dos níveis de estoque - Os estoques são reconhecidos, tradicionalmente, como uma segurança para manter o processo de produção quando ocorrem problemas ou defeitos que poderiam ocasionar sua parada.

- O JIT entende que o excesso de estoque reduz a necessidade de investigar e resolver os problemas que ficam encobertos por ele. Isto força os problemas de produção e qualidade a virem à tona para serem solucionados. À medida que o problema é localizado e solucionado, a linha de produção é capaz de atender às necessidades do processo de manufatura sem excesso de estoques, aumentando dessa forma o número de vezes que o estoque é movimentado durante o ano. A rotatividade do estoque é uma medida de eficiência da empresa na administração de materiais.

- redução ao mínimo dos tempos de preparação (setup) de máquinas - A redução do tempo de preparação leva à redução do lote produzido e, conseqüentemente, do estoque. Além disso, contribui para a redução do tempo de produção (lead time), que também é uma meta do JIT.

- redução dos tamanhos de lotes - Com o tamanho dos lotes reduzido, obtém-se como vantagem a redução dos estoques intermediários e do produto final. Além disso, se houver problemas de qualidade em um lote e este tiver que ser descartado, o custo de perda é menor.

- flexibilidade de manufatura - O JIT aumenta a flexibilidade de resposta do sistema pela redução dos tempos envolvidos no processo. Esta redução permite que o sistema produtivo seja mais flexível em relação às variações da composição (mix) de produtos (CORRÊA E GIANESI, 1993).

Segundo Smith (1989), a obtenção destes objetivos está associada à implementação de:

- controle de qualidade total

- É a visão do padrão de qualidade na empresa como um todo, com o objetivo de eliminar os problemas dessa natureza. O JIT procura diminuir a importância da inspeção como função de garantia de qualidade, e aumentar a importância do controle de qualidade como função de prevenção. Realizar tarefas corretamente assegura a qualidade do produto, o que, por sua vez, leva a uma redução dos custos associados aos desperdícios e às perdas.

- manufatura celular- É uma forma de organizar a produção baseada na divisão dos produtos finais em famílias com processo de fabricação similar. Uma vez as famílias identificadas, há a formação de células de manufatura, que têm como principais vantagens a redução do tempo gasto com 
a preparação de máquinas e com a movimentação de materiais.

- envolvimento dos operários - Os operários são estimulados a participarem da resolução dos problemas de produção e a garantirem a manutenção de equipamentos. Além disso, são treinados para a operação de diferentes tipos de máquinas, possibilitando sua utilização com maior eficiência, pois, quando não são necessários em suas próprias funções, são designados para outras, não ficando, assim, ociosos. Este estímulo ao envolvimento dos empregados possibilita a redução de custos operacionais e a melhoria de qualidade.

- manutenção preventiva - Esta tem como objetivo evitar paradas na fabricação. Durante os intervalos de produção os equipamentos são avaliados.

- carregamento uniforme - Com o objetivo de manter o fluxo contínuo, o plano mestre de produção (responsável pelo planejamento das quantidades a serem produzidas, relativas a cada produto durante certo período de tempo) fixa a produção diária do mesmo número de produtos finais, dentro de um determinado período de tempo (um mês, por exemplo), permitindo, assim, a regularidade e a estabilidade na utilização da capacidade do equipamento (recursos produtivos).

- fluxo balanceado de trabalho - Em empresas que produzem produtos finais diferentes, é importante distribuir uniformemente a carga nos centros de trabalho, para evitar sobrecarga em uns e ociosidade em outros. Por este motivo, adota-se um programa de produção em que diariamente é produzida a mesma proporção de cada produto durante o horizonte de planejamento determinado pelo carregamento uniforme.

- JIT no fornecedor- É uma extensão dos conceitos desta metodologia para "fora da fábrica", tendo como objetivo obter um freqüente número de pequenas remessas de componentes, itens e matérias-primas com alta qualidade, apenas quando a fábrica precisar.

- sistema kanban de produção - Sistema de controle de chão de fábrica baseado na idéia de que uma operação em um estágio dispara o início de uma operação em um estágio predecessor (anterior), ou seja, o material de produção é "puxado" pelo sistema à medida que se torna necessário.

Portanto, uma das marcas distintas desta metodologia é a simplicidade e a pouca necessidade de investimento de capital e de recursos humanos. Ela encoraja a gerência a resolver os problemas ao invés de encobri-los com excesso de estoque.

O JIT afeta o sistema PCP basicamente no planejamento tático e operacional, pois possui ferramentas para o controle de Chão de Fábrica e 
Compras. Indiretamente, influencia também o Gerenciamento da Demanda.

Um dos elementos mais importantes do JIT é o Sistema Kanban de Produção. Este é considerado um sistema de puxar, que se caracteriza pela retirada de itens dos estágios predecessores (anteriores) à medida que o estágio sucessor os consome em seu processo de produção. O seu objetivo básico é minimizar o estoque em processo (MONDEN, 1983 e SCHONBERGER, 1982).

Literalmente traduzido, "kanban" significa "anotação visível"; e de modo mais geral "cartão".

O uso de cartões na indústria de manufatura não se iniciou com a idéia do sistema Kanban. Eles têm sido usados, de uma forma ou de outra, ligados ao trabalho em processamento (emissões de ordem de trabalho, folhas de anotações, etc.).

No sistema Kanban, os cartões são utilizados para autorizar a produção ou transporte de certa quantidade de itens. O "kanban" contém informações sobre o tipo e a quantidade de itens, a operação (produção ou transporte) que está autorizando e o local onde o item é armazenado. A FIG. 1, mostra um formato típico de "kanban":

\begin{tabular}{|c|c|c|c|c|c|c|c|}
\hline LINHA DE & & & & & ESTÁGIO & POSIERIOR: & $4 K$ \\
\hline \multirow[t]{2}{*}{ PRODUCÄO: } & \multirow[t]{2}{*}{$F$} & & & & & LOCACÄO: & A-12 \\
\hline & & \multicolumn{2}{|c|}{ NÚMERO DO KANBAN: } & $7 / 12$ & & & \\
\hline \multicolumn{2}{|c|}{ No DO ITEM: } & \multicolumn{2}{|c|}{$33331-35010$} & & & & \\
\hline \multicolumn{2}{|c|}{ NOME DO ITEM: } & \multicolumn{2}{|c|}{ ENGRENAGEM } & & & & \\
\hline \multicolumn{4}{|c|}{$\begin{array}{ll}\text { CONT AINER TIPO: } & 6 \\
\end{array}$} & & & LOCACÄO: & c-8 \\
\hline \multicolumn{3}{|c|}{ CAPACIDADE DO CONTAINER } & 50 & & ESTÁGIO & ANTERIOR: & $4 K$ \\
\hline
\end{tabular}

FIGURA 1 - Estrutura de um "kanban".

Fonte: MONDEN, 1983.

Um "kanban" leva consigo as seguintes informações:

- nome e número do item;

- quantidade de itens (geralmente igual à capacidade do "container");

- estágio (célula de trabalho) anterior;

- estágio posterior;

Pode conter outras informações, como o tipo de embalagem, número de "kanbans" idênticos, informações específicas do item (cor, por exemplo), etc.

Segundo Nahmias (2001), o uso desse sistema pode ser resumido através do esquema: os itens são produzidos no estágio anterior (predecessor), armazenados imediatamente em um ponto de estoque e, 
subseqüentemente, transportados para o estágio posterior (sucessor). A operação desse sistema tem os passos indicados nos locais apropriados na FIG. 2.

É necessário aqui definir os dois tipos de "kanban", que são:

- "kanban" de requisição: é aquele usado para a retirada de itens do estoque, que serão usados no próximo estágio.

- "kanban" de produção: é aquele que tem a função de repor o estoque.. FIG.2:

Os passos do processo são indicados nos locais apropriados na

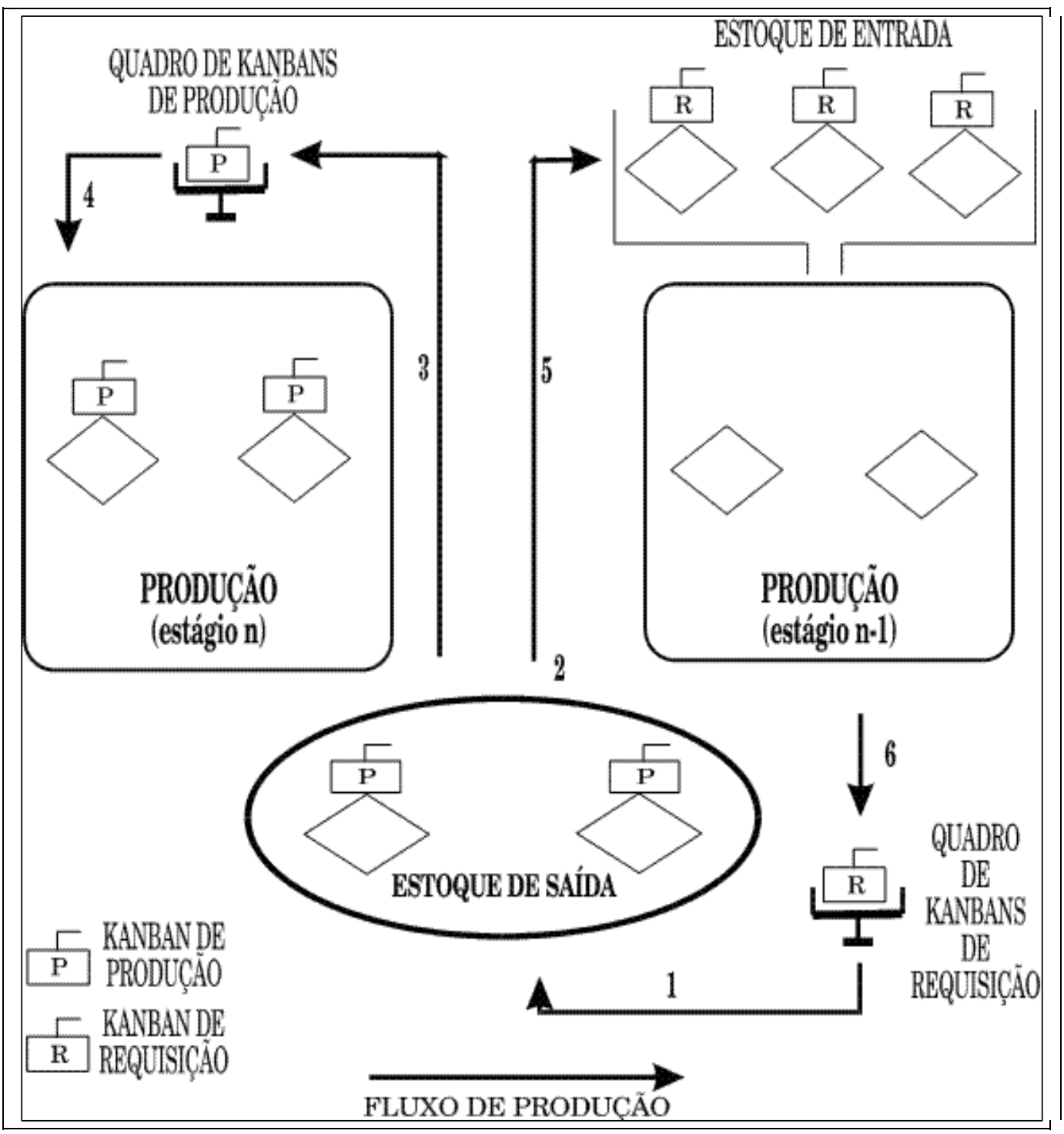

FIGURA 2 - Sistema kanban de produção de dois cartões .

Fonte: NAHMIAS, 2001.

1. Quando o número de "kanbans" de requisição alcança um nível pré-determinado no Quadro de "kanban" de Requisição, um trabalhador leva esses "kanbans" para o estoque; 
2. O trabalhador, no ponto de estoque, compara o número do item do "kanban" de requisição com o de produção;

3. Se estes números forem iguais, ele remove do "container" o "kanban" de produção, que é colocado no Quadro de "kanban" de Produção no estágio anterior, e associa ao "container" o "kanban" de requisição, deixando-o no estoque;

4. A produção no estágio anterior é executada segundo uma prioridade estabelecida no Quadro de "kanban" de Produção;

5. Um trabalhador transporta os "containers" do estoque para o estágio posterior e os deixará na área de espera, onde ficarão até que sejam requisitados;

6. Quando os itens começam a participar da produção no estágio posterior, o "kanban" de requisição é removido e colocado no Quadro de "kanban" de Requisição;

Assim, o número de "kanbans" no sistema promove o controle do estoque intermediário, através do "kanban" de requisição, e a programação da produção, pelo "kanban" de produção.

No sistema Kanban de dois cartões, o número de "kanbans" de produção é igual ao número de "kanbans" de requisição, pois não existe requisição se não há produção, e vice-versa.

Existem também os sistemas Kanban de um cartão, que se caracterizam por possuir apenas um local de estoque entre duas estações de trabalho. Yavuz e Sartir (1995) comentam que freqüentemente o sistema Kanban de um cartão é usado como estágio de desenvolvimento para o sistema Kanban de dois cartões.

O uso do sistema Kanban de dois cartões está principalmente associado à distância entre duas estações de trabalho, ou seja, quando, por alguma razão, um estágio de produção (estação de trabalho) encontra-se distante de seu sucessor.

\section{A metodologia JIT e o sistema KANBAN de produção sob o enfoque da ciência da informação}

No mundo atual, a alta competitividade provoca a busca contínua de novos métodos e técnicas para a obtenção de produtos com menor custo e melhor qualidade. O desenvolvimento de melhores estratégias se tornou uma questão de sobrevivência, o que tem proporcionado uma grande revolução nos processos de planejamento e controle da produção.

Um dos principais pilares para a obtenção desses novos métodos e técnicas é o estudo e a manipulação da informação e do conhecimento, que irão apontar para a direção correta da transformação.

Assim, a Ciência da Informação tem sido cada vez mais valorizada, pois é a responsável pelo estudo das propriedades da informação, bem como pela análise dos processos de sua construção, de sua comunicação e de seu uso. 
Neste trabalho, desde a apresentação da empresa por meio do sistema PCP (Planejamento de Controle de Produção) até o sistema Kanban de Produção, observa-se que ocorre a manipulação e a transmissão da informação e do conhecimento.

Isso pode ser avaliado nas três fases distintas de planejamento da estrutura organizacional do sistema PCP e no fluxo de informação e conhecimento estratégico representados na FIG 3.

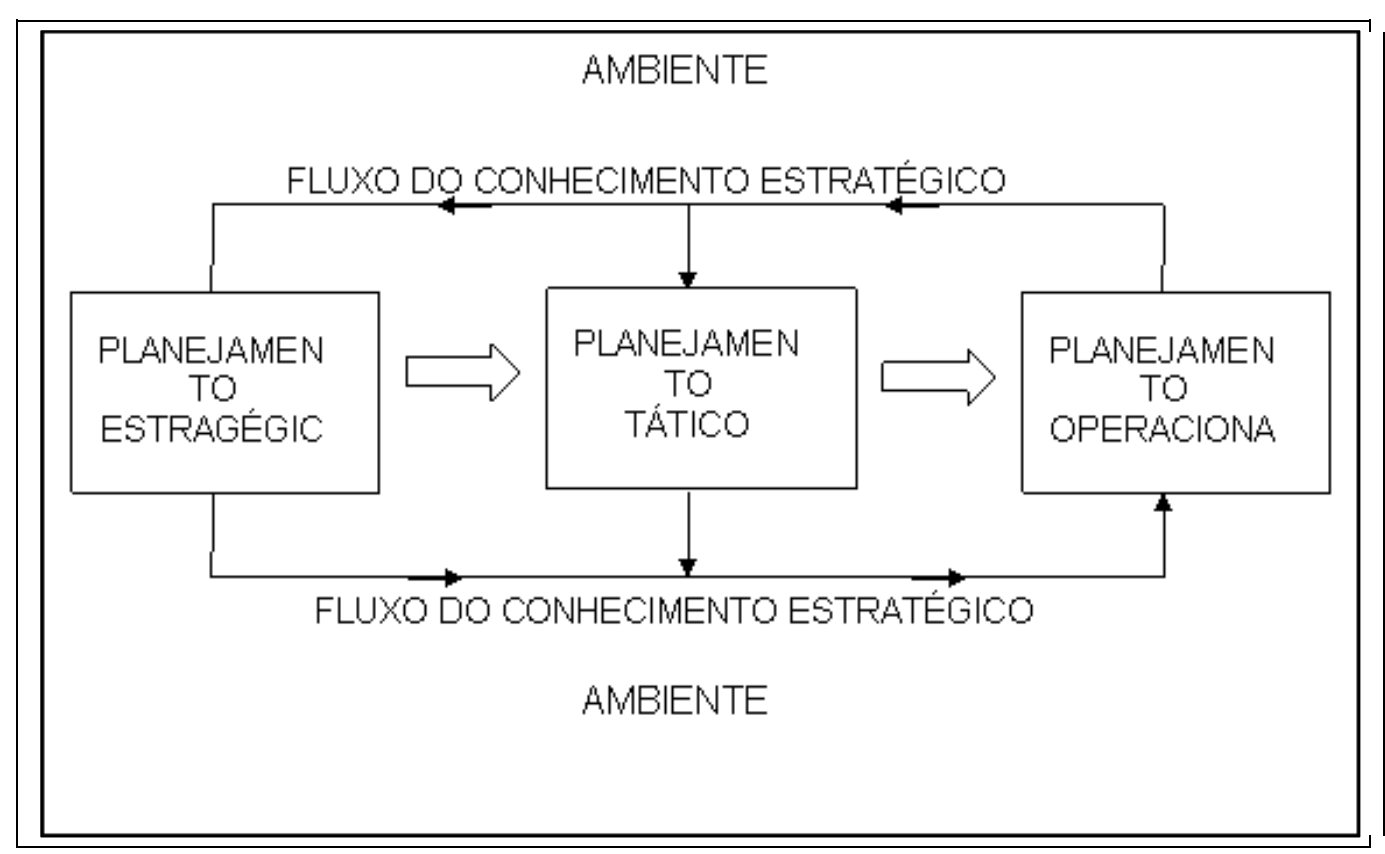

FIGURA 3 - Fluxo Básico do Sistema PCP.

Fonte: VOLLMANN, 1997.

Verifica-se que a organização necessita de um monitoramento externo (contato com o ambiente) que permita a sua diferenciação, perante os seus clientes, dos seus concorrentes. As informações estratégicas são passadas para o planejamento tático que, através do conhecimento estratégico explícito, define o planejamento operacional que disponibiliza a informação não estratégica sobre a produção. Entretanto, verifica-se que o fluxo de conhecimento estratégico não é em uma única direção, é cíclico e contínuo. A comunicação contínua entre as três fases do planejamento, com a troca de conhecimento, permite a atualização rápida da estratégia da organização, possibilitando assim que ela se diferencie dos concorrentes, assumindo vantagem competitiva no mercado.

Dados por si só não são informação; precisam ser caracterizados e padronizados adequadamente para que se transformem em informação, para que permitam a geração de ações que levem à inovação. O JIT tem como premissa a simplicidade, procurando eliminar todos os excessos dentro da empresa, principalmente na área de produção. É óbvio que uma organização enxuta (sem excessos e desperdícios) possibilita a obtenção 
de dados que realmente são relevantes, permitindo um processo de controle que rapidamente identifica distorções existentes e ajuda no crescimento da mesma.

O JIT tem um grande impacto no sistema PCP. Ele se mostra extremamente competente para a execução do Controle de Chão de Fábrica e Compras, oferecendo um potencial para a redução de custos, trabalho em processo, tempo total de produção; e proporciona um melhor planejamento em Compras. Além disso, reduz a complexidade do planejamento de necessidades de materiais, e causa também impacto no gerenciamento da demanda, pois, como produz para entregar, o nível de capacidade de entrega sofre mudanças. Ou seja, o JIT torna o sistema PCP mais ágil e flexível, pois elimina os desperdícios.

Nonaka e Takeuchi (1997) afirmam que a criação do novo conhecimento é produto da interação dinâmica entre todos os funcionários da empresa (funcionários de chão de fábrica, especialistas, gerentes, etc.). Nesse sentido, analisando as ferramentas que a metodologia JIT utiliza para a obtenção de seus objetivos, é possível verificar que todos os trabalhadores da organização são valorizados e envolvidos no processo produtivo como elementos chaves para a sua execução.

Portanto, o JIT provoca a conscientização de que os gerentes e engenheiros são aqueles que possuem o conhecimento explícito e são os responsáveis pelo suporte para a resolução de problemas encontrados pelos outros trabalhadores. Esses outros empregados possuem 0 conhecimento tácito, pois, se a empresa quer realizar suas tarefas corretamente na primeira vez, o trabalhador que a executa é que deve fazê-lo. É ele que conhece os problemas encontrados ao se tentar, na primeira vez, "fazer o correto".

A valorização dos empregados pelo JIT permite a explicitação do conhecimento tácito por eles mesmos, na medida em que estes são incentivados a resolver os problemas existentes na linha de produção, durante o processo. Esta transformação do conhecimento tácito em explícito é um grande ganho para a organização, que acaba assumindo a posse deste conhecimento que estava apenas na esfera dos empregados.

O JIT incentiva também todos os trabalhadores a opinarem sobre as mudanças associadas direta ou indiretamente a eles, procurando, através da interação entre os funcionários, obter um conhecimento estratégico mais realista e adequado.

Esta relação e a valorização dos funcionários, em todos os níveis organizacionais, permitem a utilização do conhecimento tácito e do conhecimento explícito como complementos um do outro, o que segue o modelo dinâmico da criação do conhecimento de Nonaka e Takeuchi (1997), ancorado no pressuposto crítico de que o conhecimento humano é criado e expandido através da interação social entre o conhecimento tácito e o conhecimento explícito. Para eles, a "conversão do conhecimento" (interação entre o conhecimento explícito e tácito) não está confinada dentro de um indivíduo, mas é um processo social entre indivíduos. 
O estoque tem que ser evitado, pois esconde problemas que poderiam ser eliminados. Esconder problemas gera dados incorretos e consequentemente informações que levarão a decisões erradas.

Os erros que ocorrem durante o processo não são considerados como "Monstros", mas sim como "Tesouros" (SCHMENNER, 1992) que permitem a compreensão das razões pelas quais o processo não está agindo corretamente, gerando um conhecimento tácito que evita a repetição de problemas e leva a melhorias no processo como um todo.

Sistemas tradicionais consideram os fornecedores como adversários que podem prejudicá-los a qualquer momento, com o atraso na entrega de mercadoria ou com o aumento nos preços. Portanto, ter vários fornecedores em disputa facilita a negociação com eles. A informação estratégica do fornecedor é usada, pela organização, como ferramenta para acirrar esta disputa, "facilitando" o seu relacionamento como os mesmos.

Em uma empresa que utiliza a metodologia JIT, os fornecedores são co-trabalhadores, são considerados como uma extensão da mesma. A informação estratégica do fornecedor é utilizada para a formação de parcerias sólidas que permitam à empresa possuir o número mínimo e necessário de fornecedores. A empresa também tem a possibilidade de obter o conhecimento tácito e formal do fornecedor, na medida em que este é incentivado a participar nos processos internos da produção. Este tipo de relacionamento produz informações mais concretas e eficazes.

A produção contínua, sem perdas e desperdícios, apresentada pelo JIT, necessita de um sistema de produção no chão de fábrica, que permita a sua realização. O Sistema Kanban de Produção é um sistema de informação com a finalidade de programar e controlar harmoniosamente a quantidade de produção em todo o processo.

Nahmias (2001) coloca que uma das preocupações na implementação do Sistema Kanban é o sistema de informação a ser utilizado entre as estações de trabalho (estágios), pois a direção do fluxo de informação é contrária ao fluxo de produção. Considere, por exemplo, o sistema de produção em série com seus estágios, mostrado na FIG. 4.

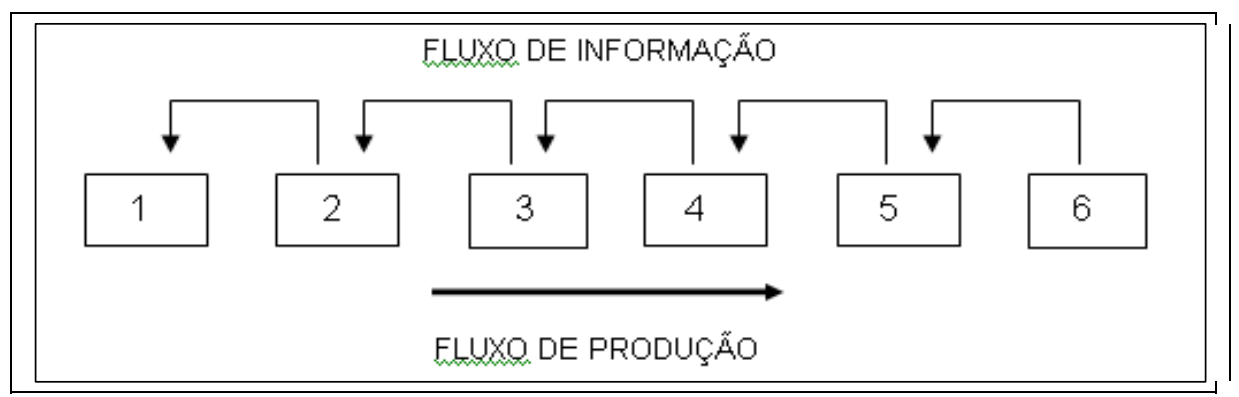

FIGURA 4 - Sistema manual de Informação.

Fonte: NAHMIAS, 2001.

Se, por exemplo, uma rápida mudança de demanda ocorrer no sexto estágio, essa mudança é transmitida para o quinto estágio, depois para o 
quarto, e assim por diante. Um atraso considerável pode ocorrer desde o instante em que a mudança aconteceu até a informação chegar ao primeiro estágio.

Um sistema centralizado de informação auxilia na diminuição deste problema, pois a informação chegará a todos os estágios simultaneamente. A FIG. 5 esquematiza um sistema centralizado de informação.

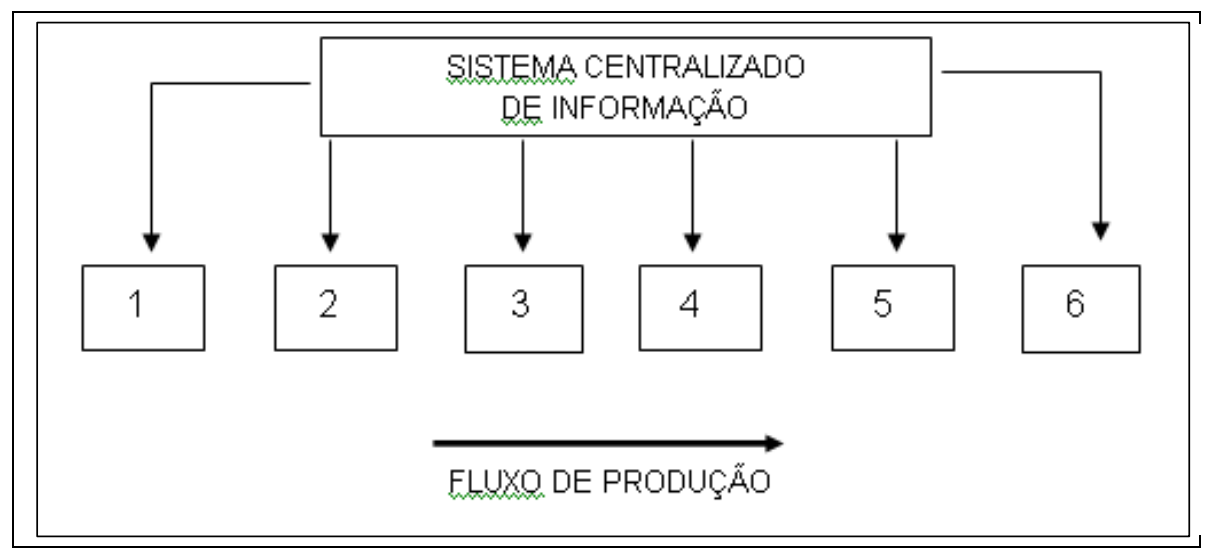

FIGURA 5 - Sistema centralizado de informação.

Fonte: NAHMIAS, 2001.

A centralização do sistema de informação permite, além do aumento da velocidade da transmissão, uma melhoria na qualidade do conhecimento estratégico obtido. Informações estratégicas qualitativas, quantitativas e mistas podem ser adquiridas por meio do monitoramento interno, e encaminhadas para os seus respectivos destinatários.

Existe também o Kanban eletrônico, que nada mais é do que um sistema de informação entre a empresa e o fornecedor, com a finalidade de possibilitar que o Kanban de requisição chegue o mais rápido possível ao fornecedor. Este pode ser através de telefone, computador, etc.

Destaca-se, ainda, que o compartilhamento do conhecimento da organização com o fornecedor possibilita um benefício mútuo: o fornecedor, por meio de uma melhor visualização do processo, pode se planejar melhor para atender às necessidades da empresa. Esta, por sua vez, se beneficia com o atendimento de suas requisições de materiais, sem a necessidade de grandes estoques (o menor possível).

Portanto, um fluxo de informação rápido e eficaz é de grande importância para a eficiência do JIT.

\section{Comentários finais}

Num mundo onde a alta tecnologia proporciona mudanças em tempo quase real, a obtenção rápida e correta da informação e do conhecimento tornou-se extremamente necessária e valorosa.

Barreto (1994) diz que "como elemento de organização, a informação norteia o homem em sua vida, no seu destino". O indivíduo 
que não se atualiza, torna-se obsoleto, impossibilitando-se de realizar o seu próprio trabalho com qualidade.

Nas organizações, a desatualização leva a perdas que também podem ser fatais. Todo mecanismo de funcionamento de uma organização gira em torno do monitoramento externo e interno, que possibilitam a obtenção de informações estratégicas que levem a um conhecimento estratégico para nortear os rumos da mesma.

Shermerhorn, Hunt e Osborn (1999) consideram a tomada de decisão como um processo de escolha de um curso de ação para lidar com um determinado problema ou oportunidade. Seguindo esta definição, Oliveira (2005) afirma que a tomada de decisão tem origem na percepção de um problema ou na realidade em evidência que exija alguma ação. Neste contexto, a informação é vista como um redutor de incertezas que auxilia na tomada de decisão.

Em uma empresa, o JIT e o Sistema Kanban favorecem a simplificação do processo de produção, a otimização e a valorização na utilização dos empregados, a eliminação de erros e a redução de custos (eliminando os gastos desnecessários), reduzindo, assim, as incertezas e auxiliando todos os níveis de gerência.

Em seu livro, Nonaka e Takeuchi (1997) fazem uma análise do sucesso das empresas japonesas avaliando, como um dos principais pontos deste sucesso, a forma como o conhecimento é tratado. Segundo eles, a visão ocidental está enraizada nas tradições administrativas em que o conhecimento é necessariamente explícito (formal e sistemático). Já as empresas japonesas tratam o conhecimento como algo dificilmente visível e exprimível, que está profundamente enraizado nas ações e nas experiências de um indivíduo, bem como em suas emoções, valores ou ideais. A metodologia JIT, neste sentido, pode ser vista como um método para a obtenção da criação desses novos conhecimentos, bem como para a transformação do conhecimento tácito apurado em seus processos em conhecimento explícito, pois seus principais elementos procuram estimular estes conceitos de interação tanto interna como externamente.

Resumindo, o foco e a base de todos os conceitos e ferramentas do JIT é a informação. Sua definição, de uma forma sintética e correta, sua qualidade e sua distribuição, mostrando que ela é o pilar de um conhecimento estratégico efetivo que proporciona a capacidade de gerar um plano estratégico melhor para a organização em todo o seu processo de produção.

\section{Referências}

BARRETO, A. A. A Questão da informação. Revista São Paulo em Perspectiva, São Paulo, v. 8, n. 4, p. 3-8, 1994.

. O que é informação e o que é ciência da informação. Jornal da Ciência, n. 1802, jun./2001. Opinião e Realidade. Disponível em: <http://paginas.terra.com.br/educacao/br recursosminerais/informac ao.html>. Acesso em: 02 jun. 2006. 
BUCKLAND, M. K. Information as thing. Journal of American Society for Information Science, v.42, n. 5, p. 351-360, 1991

BUFFA, E. S.; SARIN, R. K. Modern production / operations management. New York: John Wiley \& Sons, Inc., 1987.

CORRÊA, L. H.; GIANESI, I. Just-in-time, MRP II e OPT: um enfoque estratégico. São Paulo: Atlas, 1993.

DAVENPORT, T.; PRUSAK, L. Conhecimento empresarial. Rio de Janeiro: Campus, 1999.

FERNANDEZ-MOLINA, J. C. Enfoques objetivo y subjetivo del concepto de informacion. Revista Española de Documentación Cientifica, v.17, n. 3, p. 320-331, 1994.

GUIMARÃES, L. F. A. Just-in-time. Campinas: Alínea, 1998. (Coleção Tópicos Atuais em Administração, v 1).

HUOTARI, M-L.; WILSON, T. D. Determining organizational information needs: the critical success factors approach. Information Research, v.6 n.3, Apr. 2001.

LE COADIC, Y-F. A. Ciência da informação. Brasília: Briquet de Lemos Livros, 1996.

MIRANDA, R. C. R. O uso da informação na formulação de ações estratégicas pelas empresas. Ciência da Informação, Brasília, v. 28, n. 3, p. 286-292, set./dez. 1999.

MONDEN, Y. Toyota production systems. Atlanta: Industrial Engineering and Management Press / Institute of Industrial Engineers, 1983.

Applying just-in-time: the american and japanese experience.

Atlanta: Industrial Engineering and Management Press / Institute of Industrial Engineers, 1986.

NAHMIAS, S. Production and Operations Analysis. 4. ed. Boston: McGrawHill/Irwin, 2001.

NONAKA, I.; TAKEUCHI, H. Criação de conhecimento na empresa: como as empresas japonesas geram a dinâmica da inovação. 11. ed. Rio de Janeiro: Campus, 1997.

OLIVEIRA, S. L. G. Gestão da informação e do conhecimento: análise dos processos de tomada de decisão dos gestores da saúde pública de Campinas/SP. 108 f. Dissertação (Mestrado em Ciência da Informação) Pontifícia Universidade Católica de Campinas, Campinas, 2005.

ROSES, C. F. M. Um Estudo sobre os paradigmas de gestão do processo do século $X X$ à luz da teoria institucional, da teoria contingencial e do paradigma de Kuhn. Revista Administração On Line, v. 2, n. 4, out./dez. 2001. Disponível em: <http://www.fecap.br/adm online/>. Acesso em: 02 jun. 2006 
SCHMENNER, R.W. Production/operations Management. 5. ed. New York: Macmillan Publishing Company, 1993.

SCHONBERGER, R. J. Japanese manufacturing techniques. New York: The Free Press / Macmillan, 1982.

SETZER, V. W. Meios eletrônicos e a educação: uma visão alternativa. São Paulo: Escrituras, 2001. (Coleção Ensaios Transversais, v. 10).

SHERMERHORN, J. R.; HUNT, J. G.; OSBORN, R. N. Fundamentos do comportamento organizacional. 2. ed. Porto Alegre: Bookman, 1999,

SMITH, S. A. Computer based production and inventory control. New Jersey: Printice Hall, 1989.

VALENTIM, M. L. P. Inteligência competitiva em organizações: dado, informação e conhecimento. DataGramaZero, Rio de Janeiro, v.3, n.4, ago. 2002.

VOLLMANN, T. E.; LEE, W. B.; WHYBARK; D. C. Manufacturing planning and control systems. 4. ed. Boston: McGraw Hill, 1997.

YAVUZ, I. H.; SATIR, A. A Kanban-based simulation study of a mixed model just-in-time manufacturing line. International Journal of Production Research, v. 33, n.4, p. 1027-1048, 1995. 